\title{
Tuz Gölü (Aksaray)'nde Bazı Katyon ve Anyon Değerlerinin Belirlenmesi
}

\author{
The Determination of Some Anions and Cations of Tuz Lake (Aksaray)
}

\section{Mine KIRKAĞAÇ*}

Ankara Üniversitesi Ziraat Fakültesi Su

Ürünleri Mühendisliği Bölümü

kirkagac@agri.ankara.edu.tr

(iD) 0000-0003-0189-802X

\section{Abdolsaleh QARANJIKI}

s.qaranjiki@yahoo.com

(iD) 0000-0001-6889-0319

*Sorumlu yazar

Gönderilme Tarihi : 2 Temmuz 2020

Kabul Tarihi : 3 Eylül 2020

\section{Özet}

Tuz Gölü'nde, bazı anyon ve katyonların düzeyinin ortaya konmasının amaçlandığı çalışma, Mart-Temmuz 2014 tarihleri arasında, gölün batısında bir, gölün doğusunda seçilen dört istasyonda yürütülmüştür. Araştırma süresince aylık olarak belirlenen bazı katyon (Sodyum- $\mathrm{Na}^{+}$, Magnezyum- $\mathrm{Mg}^{2+}$, Kalsiyum- $\mathrm{Ca}^{2+}$, Potasyum-K $\mathrm{K}^{+}$) ve anyon (Klorür-Cl', Sülfat- $\mathrm{SO}_{4}{ }^{2-}$, Bikarbonat- $\mathrm{HCO}_{3}^{-}$) ortalama değerleri arasındaki farklılıklar aylara ve istasyonlara göre istatistiki olarak önemli bulunmuştur $(p<0,05)$. Tuz Gölü'nde baskın katyon $\mathrm{Na}^{+}$olup, bunu sirasiyla, $\mathrm{Mg}^{2+}$, $\mathrm{Ca}^{2+}, \mathrm{K}^{+}$, anyonlardan ise $\mathrm{Cl}^{-}$baskın olup, sirasiyla, $\mathrm{SO}_{4}^{2-}$, $\mathrm{HCO}_{3}$-izlemiştir.

$\mathrm{Bu}$ çalışmada gölün anyon ve katyon değerleri, geçmiş yıllarda belirlenen düzeye göre belirgin bir değişim göstermemiştir. $\mathrm{Bu}$ bağlamda, göldeki Artemia populasyonunun kaybolmasında gölün fiziksel, kimyasal ve biyolojik açıdan uzun dönemli izlenmesi önem arz etmektedir.

Anahtar sözcükler: Tuz Gölü, anyonlar, katyonlar, Artemia 


\begin{abstract}
The study aimed at revealing the level of some anions and cations in Tuz Lake, was carried out between March and July 2014, in stations selected one station from the west region and four stations from the east region of the lake. Differences in the average values of some cation

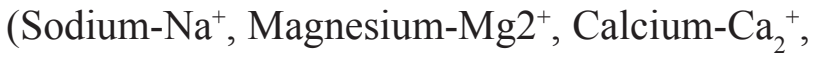
Potassium- $\mathrm{K}^{+}$) and anion (Chloride-Cl', Sulfate$\mathrm{SO}_{4}{ }^{2-}$, Bicarbonate- $\mathrm{HCO}_{3}^{-}$) determined monthly during the study were found to be statistically significant $(\mathrm{p}<0.05)$. The dominant cation is $\mathrm{Na}$ + in Tuz Lake, followed by $\mathrm{Mg}^{2+}, \mathrm{Ca}^{2+}, \mathrm{K}^{+}$, and $\mathrm{Cl}^{-}$is the dominant anion, followed by $\mathrm{SO}_{4}^{2-}$, $\mathrm{HCO}_{3}^{-}$, respectively.
\end{abstract}

In this study, the anion and cation values of the Lake did not show a significant change compared to the level that determined in previous years. In this context, physical, chemical and biological monitoring of the Lake in long-term is important to determine the causes the disappearance of the Artemia population.

Key words: Tuz Lake, anions, cations, Artemia

\section{Giriş}

Tuz Gölü kapladığı geniş su alanı ile su kuşları için önemli bir kışlama alanı olup, biyoçeşitliliğin korunması açısından büyük önem taşıyan ve RAMSAR sözleşmesine göre A sınıfına giren bir sulak alandır (Anonim, 2004). Tuz Gölü ülkemizin ikinci büyük gölü olup, dışarıya akıntısı olmayan kapalı havza gölüdür. Tuzluluk oranı \%32 civarındadır ve dünyanın en tuzlu gölü olan Lut Gölü'nden sonra tuzluluk oranı açısından ikinci sırada yer almaktadır.
Tuz Gölü'nde yer altı su seviyesindeki azalma, gölü besleyen yüzey suların azalması ve iklimin kurak gitmesi ile gölde yaklaşık \%60 oranında küçülme belirlenmiştir, son yıllarda ortaya çıkan küresel ısınma ile birlikte gölü tehdit etmektedir (Anonim, 2007). Türkiye'nin en siğ gölü olarak bilinen göl kuruma, endüstrileşme, doğal kaynakların kullanılması, kentsel faaliyetlerinden ve iyi korunmamasından dolay 1 su yüzey alanı sıralamasında Beyşehir Gölünden sonra üçüncü sıraya düşmüştür (Köylü, 2017). Tuz Gölü tuz üretimi açısından önemli bir doğal kaynak olup, ülkemizin tuz ihtiyacının \%70'ni karşılamaktadır (Kılıç ve Uyanık, 2001).

Tuz Gölü'nün su kalitesi, çevresinde bulunan yerleşim alanlarından, çeşitli faaliyetlerden ve iklim değişikliğinden önemli ölçüde etkilenir. Tuz Gölü'ne dökülen bilhassa Konya gibi büyük bir şehre ait evsel, bunun dişında çevrede yapılan tarımsal faaliyetler sonucu ortaya çıkan tarımsal atıkların zaman içerisinde kontrol altına alınmaması, bölgeyi kirlilik açısından olumsuz yönde etkilemektedir (Örmeci ve Ekercin, 2005). Tuz Gölü'nün ekonomik ve ekolojik açıdan önemli olmasının yanında iklim değişikliği ve çevresel kirlilik açısından olumsuz etki altında olması araştırıcıları göle yönelik çeşitli alanlarda çalışmalara yöneltmiştir. Tuz Gölü’nün, diğer tuz göllerinde olduğu gibi, başlıca zooplanktonu olan ve tuz kristallerin kalitesini etkileyen Artemia' ya ilişkin son yıllarda çeşitli araştırmalar yapılmaktadır (Başbuğ, 1994, 1999a,1999b, Başbuğ and Demirkalp, 1997, Kırkağaç et al., 2017, Eskandari and Sayg1 2019, Yokuş and Kırkağaç 2019). 
Tuz Gölü'nde Artemiapopulasyonlarının dağılımında yıllar itibarı ile farklılıklar gözlenmiştir. Özellikle, Kırkağaç et al. (2017), yaptıkları araştırmada Artemia sp.'nın doğal alanından kaybolma tehlikesi olduğunu, bir sonraki yıl yapılan araştırmada Artemia bolluğunun arttığı bildirilmiştir (Yokuş and Kırkağaç 2019).

Tuz Gölü'nde 1994-2017 yılında yapılan çalışmalarda belirlenen Artemia sp. populasyonlarındaki dalgalanmada başta iklimsel olmak üzere, iyon kompozisyonu, $\mathrm{pH}$, hidrolojik koşullar gibi birçok faktör etkilidir. Bu çalışmada, Tuz Gölü'ndeki iyon kompozisyonunun durumunun ve Artemia populasyonunun yok olma tehlikesinin belirdiği 2014 yılında etkili olup olmadığının ortaya konması amaçlanmıştır.

\section{Materyal ve Metot}

Tuz gölü, İç Anadolu Bölgesinde yaklaşık 7400 $\mathrm{km}^{2}$ 'lik alanı ile Konya ve Aksaray İllerini de kapsayarak 4227841 ile 4337443 N kuzey enlemleri ve 470089 ile 586433 E doğu boylamları arasında yer almaktadır. Bakanlar $\mathrm{Ku}$ rulu kararı ile 2000 yılında Özel Çevre Koruma Bölgesi olarak ilan edilmiş ve koruma altına alınmıştır. Gölün genişliği $35 \mathrm{~km}$, uzunluğu 90 km ve yaklaşık alanı 1700 km²'dir. Gölü besleyen akarsular doğuda Şereflikoçhisar'dan geçen Peçenek Suyu, güneyde Ballıca ve Kırkdelik Suları ve Eşmekaya Deresi, güneybatıda Tersakan Suyu ve batıda Cihanbeyli'den gelen İnsuyu'dur (Anonim, 2007).
Araştırma, Tuz Gölü’nde, Mart-Temmuz 2014 tarihleri arasında yürütülmüştür. Göle ulaşılabilen noktalardan, gölü temsil edecek, gölün batısında bir, gölün doğusunda dört istasyon seçilmiştir (Şekil 1). Su örnekleri istasyonlardan 15 günlük periyodlarla alınmıştır. Temmuz ayında mevsime bağlı olarak su çekilmesi nedeniyle ilk üç istasyondan su örneği alınamamiştır. Su örneklerinde; Sodyum- $\mathrm{Na}^{+}$, Magnezyum- $\mathrm{Mg}^{2+}$, Kalsiyum-Ca ${ }^{2+}$, Potasyum-K ${ }^{+}$, Klorür-Cl-, Sülfat- $\mathrm{SO}_{4}{ }^{2-}$, Bikarbonat- $\mathrm{HCO}_{3}^{-}$analizleri, titrimetrik yöntemle APHA (1980)'e göre Tarım ve Orman Bakanlığg1, Toprak-Gübre ve Su Kaynakları Merkez Araştırma Laboratuvarı Su Analizleri Laboratuvarında yapılmıştır. Değerler aylık ortalama olarak hesaplanmıştır.

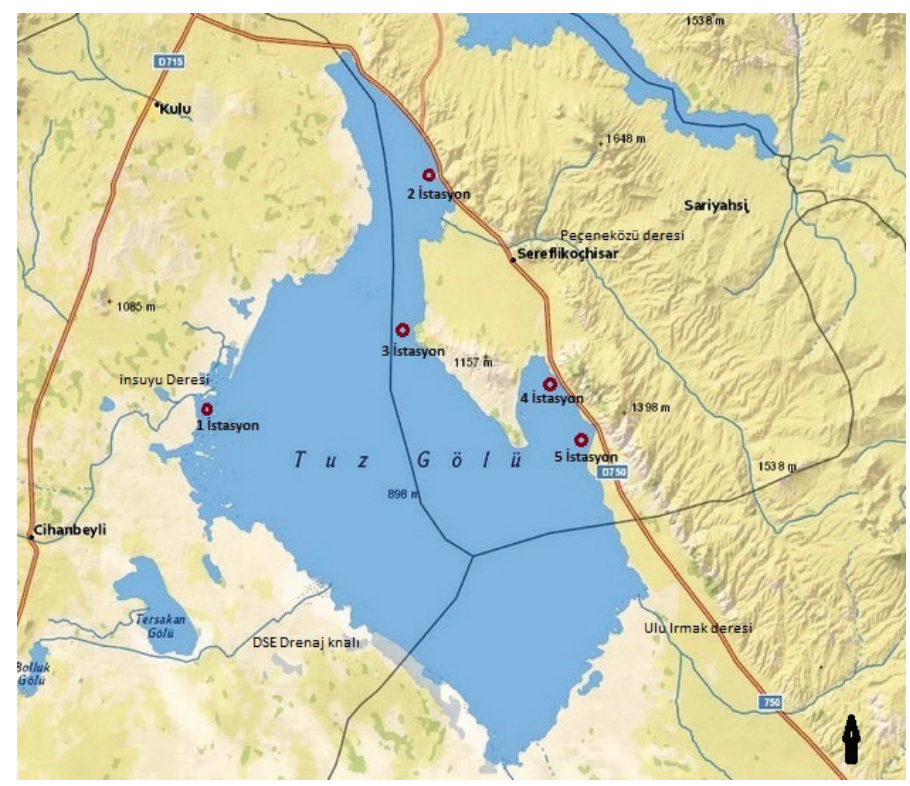

Şekil 1. Tuz Gölü ve örnekleme istasyonları

Tuz Gölü'nde, Mart-Temmuz 2015 tarihleri arasında, su sicaklığı $0,84 \pm 0,05 \quad{ }^{0} \mathrm{C} \quad$ ile $30,60 \pm 0,55{ }^{0} \mathrm{C}$, çözünmüş oksijen $1,63 \pm 0,13$ $\mathrm{mg} / \mathrm{l}$ ile 6,91 $\pm 0,08 \mathrm{mg} / \mathrm{l}, \mathrm{pH} \quad 7,53 \pm 0,02$ ile $7,89 \pm 0,01$, tuzluluk $405 \pm 10 \mathrm{~g} / 1$ ile $217 \pm 7 \mathrm{~g} / 1$, 
elektrik iletkenliği $118 \pm 1 \mathrm{mS} / \mathrm{cm}$ ile $214 \pm 1 \mathrm{mS} /$ $\mathrm{cm}$ arasında değişmiştir. Su derinliği, sı̆̆ bölgede $3 \pm 1 \mathrm{~cm}$ ile $28 \pm 1 \mathrm{~cm}$, derin bölgede ise $8 \pm 1 \mathrm{~cm}$ ile $20 \pm 1 \mathrm{~cm}$ arasında ölçülmüştür (Kırkağaç et al., 2017).

Elde edilen verilerin değerlendirilmesinde varyans analizi (ANOVA) ve Duncan testi (SPSS 17 paket programı) kullanılmıştır ve istatistiki hesaplamalar Kesici ve Kocabaş (2007)'nin belirttiği esaslara göre yapılmıştır.

\section{Bulgular}

Tuz Gölü’nde Mart-Temmuz 2014 tarihlerinde anyonlardan; klorür, sülfat ve bikarbonat değerleri belirlenmiş, sonuçlar örnek alınan aylara ve istasyonlara göre Çizelge 1'de verilmiştir.
Araştırma süresince ortalama klorür, sülfat ve bikarbonat değerlerinin istasyonlardaki aylık değişimleri arasındaki farklılık istatistiki olarak önemli bulunmuştur $(\mathrm{p}<0,05)$. Klorür değerleri en düşük Mart ayında bulunmuştur. Bununla birlikte, araştırma süresince genel olarak en yüksek değerler 2. istasyonda ölçülmüştür. En yüksek sülfat değerleri araştırma süresince 1 . istasyonda belirlenmiştir. Bikarbonat değerleri ise istasyonlarda Haziran ve Temmuz aylarında alınan örneklerde daha yüksek bulunmuştur.

Araştırma süresince ortalama klorür, sülfat ve bikarbonat değerlerinin aylık ortalamalarına bakıldığında; Klorür değerleri Mayıs ayından sonra bir yükselme göstermektedir. Temmuz ayında ise hafif bir azalma görülmektedir, ancak gölde su çekilmesine bağlı olarak ortalama

Çizelge 1. Tuz Gölü'nde ortalama klorür, sülfat ve bikarbonat değerleri aylara ve istasyonlara bağl1 değişimi, g/l (Ortalama \pm standart sapma) (“_“ istasyonlarda su bulunmamıştır)

\begin{tabular}{|c|c|c|c|c|c|c|}
\hline \multirow[t]{2}{*}{ Ay } & \multirow[t]{2}{*}{ Parametre } & \multicolumn{5}{|c|}{ İstasyon } \\
\hline & & 1 & 2 & 3 & 4 & 5 \\
\hline \multirow{3}{*}{$\sum_{\Sigma}^{ \pm}$} & Klorür & $119,64 \pm 1,0 \mathrm{D}^{*} \mathrm{e}^{* *}$ & $166,36 \pm 0,0 \mathrm{Da}$ & $126,2 \pm 0,0 \mathrm{Cc}$ & $125,38 \pm 0,0 \mathrm{Ed}$ & $128,3 \pm 0,0 \mathrm{~Eb}$ \\
\hline & Sülfat & $30,43 \pm 0,0 \mathrm{Ba}$ & $16,07 \pm 0,0 \mathrm{Ce}$ & $23,88 \pm 0,0 \mathrm{Bb}$ & $16,53 \pm 0,0 \mathrm{Ed}$ & $20,0 \pm 0,0 \mathrm{Dc}$ \\
\hline & Bikarbonat & $0,179 \pm 0,0 \mathrm{Cab}$ & $0,118 \pm 0,0 \mathrm{Dd}$ & $0,13 \pm 0,0 \mathrm{Dc}$ & $0,188 \pm 0,0 \mathrm{Ca}$ & $0,17 \pm 0,0 \mathrm{~Eb}$ \\
\hline \multirow{3}{*}{$\begin{array}{l}\text { 志 } \\
\text { 足 } \\
\text { Z }\end{array}$} & Klorür & $174,62 \pm 1,0 \mathrm{Cd}$ & $184,38 \pm 0,0 \mathrm{Aa}$ & $173,73 \pm 0,3 \mathrm{Be}$ & $180,24 \pm 0,0 \mathrm{Bb}$ & $176,19 \pm 0,0 \mathrm{Cc}$ \\
\hline & Sülfat & $28,55 \pm 0,0 \mathrm{Ca}$ & $13,21 \pm 0,0 \mathrm{De}$ & $20,68 \pm 0,0 \mathrm{Ac}$ & $17,66 \pm 0,0 \mathrm{Dd}$ & $23,17 \pm 0,0 \mathrm{Cb}$ \\
\hline & Bikarbonat & $0,166 \pm 0,0 \mathrm{Cc}$ & $0,183 \pm 0,0 \mathrm{Cab}$ & $0,188 \pm 0,0 \mathrm{Aa}$ & $0,186 \pm 0,0 \mathrm{Ca}$ & $0,176 \pm 0,0 \mathrm{Db}$ \\
\hline \multirow{3}{*}{ 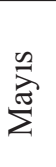 } & Klorür & $182,75 \pm 0,0 \mathrm{Aa}$ & $182,75 \pm 0,0 \mathrm{Ba}$ & $181,93 \pm 0,0 \mathrm{ABb}$ & $181,11 \pm 0,0 \mathrm{Ac}$ & $181,38 \pm 0,0 \mathrm{Ac}$ \\
\hline & Sülfat & $25,96 \pm 0,0 \mathrm{Da}$ & $21,01 \pm 0,0 \mathrm{Bd}$ & $19,35 \pm 0,0 \mathrm{De}$ & $22,85 \pm 0,0 \mathrm{Cc}$ & $23,62 \pm 0,0 b$ \\
\hline & Bikarbonat & $0,29 \pm 0,0 \mathrm{Ba}$ & $0,20 \pm 0,0 \mathrm{Bb}$ & $0,181 \pm 0,0 \mathrm{Bc}$ & $0,193 \pm 0,0 \mathrm{Ce}$ & $0,191 \pm 0,0 \mathrm{Cd}$ \\
\hline \multirow{3}{*}{ 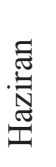 } & Klorür & $179,4 \pm 0,0 \mathrm{Ba}$ & $179,47 \pm 0,0 \mathrm{Ca}$ & $166,8 \pm 0,0 \mathrm{Ba}$ & $174,55 \pm 0,0 \mathrm{Da}$ & $181,11 \pm 0,0 \mathrm{Ba}$ \\
\hline & Sülfat & $58,22 \pm 0,0 \mathrm{Aa}$ & $37,04 \pm 0,0 \mathrm{Ab}$ & $20,67 \pm 0,0 \mathrm{Cd}$ & $32,66 \pm 0,0 \mathrm{Bc}$ & $19,48 \pm 0,0 \mathrm{Ee}$ \\
\hline & Bikarbonat & $0,68 \pm 0,0 \mathrm{Aa}$ & $0,33 \pm 0,0 \mathrm{Ab}$ & $0,15 \pm 0,0 \mathrm{Be}$ & $0,23 \pm 0,0 \mathrm{Bc}$ & $0,21 \pm 0,0 \mathrm{Bd}$ \\
\hline \multirow{3}{*}{ 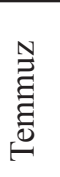 } & Klorür & & & & $179,47 \pm 0,0 \mathrm{Ca}$ & $174,55 \pm 0,0 \mathrm{Db}$ \\
\hline & Sülfat & & & & $40,7 \pm 0,0 \mathrm{Aa}$ & $38,45 \mathrm{Ab}$ \\
\hline & Bikarbonat & & & & $0,28 \pm 0,0 \mathrm{Aa}$ & $0,27 \pm 0,0 \mathrm{Aa}$ \\
\hline
\end{tabular}

*Aynı sütunda farklı büyük harf taşıyan ortalama değerler arasındaki fark istatistiki olarak önemlidir $(\mathrm{p}<0,05)$.

**Aynı satırda farklı küçük harf taşıyan ortalama değerler arasındaki fark istatistiki olarak önemlidir $(\mathrm{p}<0,05)$. 
değerler sadece iki istasyondan elde edilmiştir. Ortalama sülfat değerleri ise aylar itibarıyla artış göstermiştir. Ortalama bikarbonat değerleri artarak Mayıs ayında pik yapmış, sonra azalmıştır (Çizelge 2).
Araştırma süresince ortalama sodyum, potasyum, kalsiyum ve magnezyum değerlerinin istasyonlardaki aylık değişimleri arasındaki farklılık istatistiki olarak önemli bulunmuştur $(\mathrm{p}<0,05)($ Çizelge 3).

Çizelge 2. Tuz Gölü’nde araştırma süresince ortalama toplam klorür, sülfat ve bikarbonat değerlerinin değișimi $(\mathrm{g} / \mathrm{l})$

\begin{tabular}{|l|l|l|l|l|l|}
\hline \multirow{2}{*}{ Anyon } & \multicolumn{5}{|c|}{ Ay } \\
\cline { 2 - 6 } & Mart & Nisan & May1s & Haziran & Temmuz \\
\hline Klorür & $145,87 \pm 0,0$ & $177,83 \pm 0,0 \mathrm{Da}$ & $181,98 \pm 0,0 \mathrm{Cc}$ & $181,78 \pm 0,0 \mathrm{Ed}$ & $177,01 \pm 0,0 \mathrm{~Eb}$ \\
\hline Sülfat & $21,38 \pm 0,0 \mathrm{Ba}$ & $20,65 \pm 0,0 \mathrm{Ce}$ & $22,55 \pm 0,0 \mathrm{Bb}$ & $33,61 \pm 0,0 \mathrm{Ed}$ & $39,55 \pm 0,0 \mathrm{Dc}$ \\
\hline Bikarbonat & $0,157 \pm 0,0$ & $0,179 \pm 0,0$ & $0,817 \pm 0,0$ & $0,211 \pm 0,0$ & $0,28 \pm 0,0 \mathrm{~Eb}$ \\
\hline
\end{tabular}

*Aynı sütunda farklı büyük harf taşıyan ortalama değerler arasındaki fark istatistiki olarak önemlidir $(\mathrm{p}<0,05)$.

**Aynı satırda farklı küçük harf taşıyan ortalama değerler arasındaki fark istatistiki olarak önemlidir $(\mathrm{p}<0,05)$.

Çizelge 3. Tuz Gölü'nde ortalama sodyum, potasyum, kalsiyum ve magnezyum değerlerinin aylara ve istasyonlara bağlı değişimi, g/l (Ortalama \pm standart sapma) (““_“ istasyonlarda su bulunmamıştır)

\begin{tabular}{|c|c|c|c|c|c|c|}
\hline \multirow[t]{2}{*}{ Ay } & \multirow[t]{2}{*}{ Parametre } & \multicolumn{5}{|c|}{ İstasyon } \\
\hline & & 1 & 2 & 3 & 4 & 5 \\
\hline \multirow{4}{*}{$\sum_{\Sigma}^{ \pm}$} & Sodyum & $85,1 \pm 0,2 \mathrm{D} * \mathrm{c} * *$ & $110,4 \pm 0,1 \mathrm{Da}$ & $88,5 \pm 0,0 \mathrm{Db}$ & $82,8 \pm 0,0 \mathrm{Ce}$ & $83,5 \pm 0,0 \mathrm{Dd}$ \\
\hline & Potasyum & $0,82 \pm 0,0 \mathrm{Da}$ & $0,58 \pm 0,0 \mathrm{Dd}$ & $0,50 \pm 0,0 \mathrm{De}$ & $0,70 \pm 0,0 \mathrm{Ec}$ & $0,71 \pm 0,0 \mathrm{~Eb}$ \\
\hline & Kalsiyum & $1,27 \pm 0,0 \mathrm{Aa}$ & $0,85 \pm 0,0 \mathrm{De}$ & $1,06 \pm 0,0 \mathrm{Cb}$ & $0,93 \pm 0,0 \mathrm{Bd}$ & $1,00 \pm 0,0 \mathrm{Dc}$ \\
\hline & Magnezyum & $2,81 \pm 0,0 \mathrm{Da}$ & $2,17 \pm 0,0 \mathrm{Dd}$ & $1,79 \pm 0,0 \mathrm{De}$ & $2,73 \pm 0,0 \mathrm{Ec}$ & $2,75 \pm 0,0 \mathrm{~Eb}$ \\
\hline \multirow{4}{*}{$\begin{array}{l}\text { శ్ } \\
. \stackrel{0}{Z}\end{array}$} & Sodyum & $96,57 \pm 1,5 \mathrm{Cc}$ & $117,3 \pm 0,1 \mathrm{Ca}$ & $112,1 \pm 0,0 \mathrm{Cb}$ & $117,3 \pm 0,0 \mathrm{Aa}$ & $117,3 \pm 0,0 \mathrm{Ba}$ \\
\hline & Potasyum & $0,95 \pm 0,0 \mathrm{Cc}$ & $0,97 \pm 0,0 \mathrm{Cb}$ & $1,09 \pm 0,0 \mathrm{Ca}$ & $0,85 \pm 0,0 \mathrm{De}$ & $0,89 \pm 0,0 \mathrm{Dd}$ \\
\hline & Kalsiyum & $1,05 \pm 0,0 \mathrm{Bd}$ & $1,23 \pm 0,0 \mathrm{Cb}$ & $1,27 \pm 0,0 \mathrm{Aa}$ & $1,14 \pm 0,0 \mathrm{Ac}$ & $1,27 \pm 0,0 \mathrm{Ba}$ \\
\hline & Magnezyum & $4,05 \pm 0,0 \mathrm{Ca}$ & $3,65 \pm 0,0 \mathrm{Cb}$ & $3,34 \pm 0,0 \mathrm{Cd}$ & $3,45 \pm 0,0 \mathrm{Dc}$ & $3,35 \pm 0,0 \mathrm{Dd}$ \\
\hline \multirow{4}{*}{ 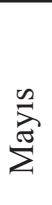 } & Sodyum & $117,3 \pm 0,2 \mathrm{Ac}$ & $119,4 \pm 0,4 \mathrm{Ab}$ & $117,49 \pm 0,0 \mathrm{Ac}$ & $117,3 \pm 0,0 \mathrm{Ac}$ & $119,98 \pm 0,0 \mathrm{Aa}$ \\
\hline & Potasyum & $1,95 \pm 0,0 \mathrm{Ba}$ & $1,2 \pm 0,1 \mathrm{Bb}$ & $1,23 \pm 0,0 \mathrm{Ab}$ & $1,01 \pm 0,0 \mathrm{Cc}$ & $1,05 \pm 0,0 \mathrm{Cc}$ \\
\hline & Kalsiyum & $1,04 \pm 0,0 \mathrm{Bd}$ & $1,43 \pm 0,0 \mathrm{Aa}$ & $1,12 \pm 0,0 \mathrm{Bc}$ & $1,13 \pm 0,0 \mathrm{Ac}$ & $1,17 \pm 0,0 \mathrm{bc}$ \\
\hline & Magnezyum & $6,15 \pm 0,0 \mathrm{Ba}$ & $3,75 \pm 0,0 \mathrm{Be}$ & $4,24 \pm 0,0 \mathrm{Bc}$ & $5,01 \pm 0,0 \mathrm{Cb}$ & $3,84 \pm 0,0 \mathrm{Cd}$ \\
\hline \multirow{4}{*}{ 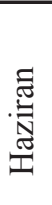 } & Sodyum & $112,12 \pm 0,6 \mathrm{Be}$ & $118,34 \pm 0,0 \mathrm{Ba}$ & $116,13 \pm 0,0 \mathrm{c}$ & $115,57 \pm 0,0 \mathrm{Bb}$ & $116,43 \pm 0,0 \mathrm{Cc}$ \\
\hline & Potasyum & $5,01 \pm 0,0 \mathrm{Aa}$ & $2,45 \pm 0,0 \mathrm{Ab}$ & $1,18 \pm 0,0 \mathrm{Bd}$ & $1,32 \pm 0,0 \mathrm{Bc}$ & $1,15 \pm 0,0 \mathrm{Be}$ \\
\hline & Kalsiyum & $0,97 \pm 0,0 \mathrm{Cc}$ & $1,27 \pm 0,0 \mathrm{Ba}$ & $1,03 \pm 0,0 \mathrm{Db}$ & $1,1 \pm 0,0 \mathrm{Cb}$ & $1,2 \pm 0,0 \mathrm{Ba}$ \\
\hline & Magnezyum & $15,08 \pm 0,0 \mathrm{Aa}$ & $7,53 \pm 0,0 \mathrm{Ab}$ & $5,07 \pm 0,0 \mathrm{Ad}$ & $6,08 \pm 0,0 \mathrm{Bc}$ & $4,53 \pm 0,0 \mathrm{Be}$ \\
\hline \multirow{4}{*}{ 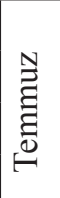 } & Sodyum & - & - & - & $117,3 \pm 0,0 \mathrm{Aa}$ & $117,3 \pm 0,0 \mathrm{Ba}$ \\
\hline & Potasyum & - & - & - & $2,18 \pm 0,0 \mathrm{Aa}$ & $1,83 \pm 0,0 \mathrm{Ab}$ \\
\hline & Kalsiyum & - & - & - & $0,85 \pm 0,0 \mathrm{Db}$ & $1,48 \pm 0,0 \mathrm{Aa}$ \\
\hline & Magnezyum & - & - & - & $8,79 \pm 0,0 \mathrm{Aa}$ & $6,25 \pm 0,0 \mathrm{Ab}$ \\
\hline
\end{tabular}

*Aynı sütunda farklı büyük harf taşıyan ortalama değerler arasındaki fark istatistiki olarak önemlidir $(\mathrm{p}<0,05)$.

**Aynı satırda farklı küçük harf taşıyan ortalama değerler arasındaki fark istatistiki olarak önemlidir $(\mathrm{p}<0,05)$. 
Araştırmada, sodyum değerleri Mart ayında en düşük bulunmuştur. Bununla birlikte, araştırma süresince genel olarak en yüksek değerler 2. istasyonda ölçülmüştür. Potasyum değerleri araştırma süresince Nisan ayı dışında 1.istasyonda yüksek bulunurken, bütün istasyonlarda aylar itibarıyla artış göstermiştir. Magnezyum değerleri ise araştırma süresince en yüksek 1.istasyonda bulunmuş, aylar itibarıyla istasyonlarda artmıştır.

Araştırma süresince ortalama sodyum, potasyum, kalsiyum ve magnezyum değerlerinin aylık ortalamalarına bakıldığında; ortalama potasyum ve magnezyum değerleri artış gösterirken, ortalama sodyum ve kalsiyum değerlerinin artış1 sınırlı olmuştur (Çizelge 4). anyon ve katyon ortalama değerleri aylara ve istasyonlara göre istatistiki olarak önemli bulunmuştur $(\mathrm{p}<0,05)$.

Dünyada klorür içeren tuz gölleri yaygındır. Tuz Gölü'nde dominant anyon olarak klorür derişimleri $119,64 \pm 1,0 \quad$ ile $\quad 184,38 \pm 0,0 \quad \mathrm{~g} / 1$ arasında değişmiştir. İstasyonların ortalaması alındığında ise araştırma süresince gölün klorür derişimi 145,87 ile 181,98 g/1 arasında olmuştur. Değerler genel olarak Mayıs ayına doğru artış göstermiş ve Haziran ayında (166,8 ile 181,11 g/l) nisbeten azalmıştır. Uygun ve Şen (1978) 1976 ve 1977 yıllarında gölün klorür derişimlerini 121 ile 192,5 g/1 arasında ölçmüşler, en düşük değer Mayıs 1977'de en yüksek değer ise Kasım 1976'da kaydedilmiştir. Artemia'nın bulunduğu

Çizelge 4. Tuz Gölü'nde araştırma süresince ortalama toplam sodyum, potasyum, kalsiyum ve magnezyum değerlerinin değişimi $(\mathrm{g} / \mathrm{l})$

\begin{tabular}{|l|l|l|l|l|l|}
\hline \multirow{2}{*}{ Katyon } & \multicolumn{5}{|c|}{ Aylar } \\
\cline { 2 - 6 } & \multicolumn{1}{|c|}{ Mart } & \multicolumn{1}{|c|}{ Nisan } & \multicolumn{1}{|c|}{ May1s } & \multicolumn{1}{c|}{ Haziran } & \multicolumn{1}{c|}{ Temmuz } \\
\hline Sodyum & $90,06 \pm 0,2 \mathrm{Dc}$ & $112,14 \pm 0,1 \mathrm{Da}$ & $118,29 \pm 0,0 \mathrm{Db}$ & $115,69 \pm 0,0 \mathrm{Ce}$ & $117,3 \pm 0,0 \mathrm{Dd}$ \\
\hline Potasyum & $0,52 \pm 0,0 \mathrm{Da}$ & $0,95 \pm 0,0 \mathrm{Dd}$ & $1,28 \pm 0,0 \mathrm{De}$ & $2,22 \pm 0,0 \mathrm{Ec}$ & $2,00 \pm 0,0 \mathrm{~Eb}$ \\
\hline Kalsiyum & $1,02 \pm 0,0 \mathrm{Aa}$ & $1,21 \pm 0,0 \mathrm{De}$ & $1,17 \pm 0,0 \mathrm{Cb}$ & $1,11 \pm 0,0 \mathrm{Bd}$ & $1,16 \pm 0,0 \mathrm{Dc}$ \\
\hline Magnezyum & $2,45 \pm 0,0 \mathrm{Da}$ & $3,56 \pm 0,0 \mathrm{Dd}$ & $4,59 \pm 0,0 \mathrm{De}$ & $7,65 \pm 0,0 \mathrm{Ec}$ & $7,57 \pm 0,0 \mathrm{~Eb}$ \\
\hline
\end{tabular}

*Aynı sütunda farklı büyük harf taşıyan ortalama değerler arasındaki fark istatistiki olarak önemlidir $(\mathrm{p}<0,05)$.

**Aynı satırda farklı küçük harf taşıyan ortalama değerler arasındaki fark istatistiki olarak önemlidir $(\mathrm{p}<0,05)$.

\section{Tartışma}

Tuz Gölü'nde bir yıl süreyle yapılan bir araştırmada çeşitli katyon ve anyonların mevsimsel değerleri ortaya konmuş ve gölde bir eşik ile birbirinden ayrılmış, suları farklı bileşimde iki bölge tespit edilmiştir (Uygun ve Şen, 1978).

$\mathrm{Bu}$ araştırmada, Tuz Gölü'nde Mart-Temmuz 2014 tarihlerinde aylık olarak belirlenen bazı derin bölgede klorür derişimi Mayıs ve Haziran aylarında sirasıyla $40,9 \mathrm{~g} / \mathrm{l}$ ve $46 \mathrm{~g} / \mathrm{l}$ olarak bulunmuştur. Çamur ve Mutlu (1995), NisanTemmuz ayları arasında sığ bölgede klorür derişimi 173,10 g/1 -172,71 g/l olup haziranda pik yapmıştır, derin bölgede ise Mayıs-Temmuz ayları arasında 40,0 g/l - 91,50 g/1 olmuş ve artış eğilimi göstermiştir Eskandari (2014), Kasım 2009-Ekim tarihleri arasında yürüttükleri 
çalışmada Haziran ayında klorür derişimini 160 g/l civarında belirlerken, gölde Şubat ve Ekim ayları arasındaki ölçümler 120-190 g/1 olmuştur. Bu çalışmada değer aralıkları nisbeten diğer araştırmalarla benzer olmuştur. Ancak Artemia'nın bulunduğu istasyonlarda Mayıs ve Haziran aylarında değerler sırasıyla 181,28 g/1 ve 177,83 g/l bulunmuştur. Bu değerler Uygun ve Şen(1978)'e göre oldukça yüksektir. Bu durumun yağışlara bağlı olarak iklimsel değişimlerden kaynaklandığ1 düşünülmektedir. Tuz Gölü Havzası'nda 1975-2015 yılları verilerine göre yıllar itibarıyla sıcaklık verilerinin yükseldiği, yağış verilerinin ise azaldığ (Akın 2019). Bununla birlikte, klorürce zengin sularda Artemia populasyonunun yüksek olduğu bildirilmektedir (Litvenenko et al., 2007).

Tuz Gölü'nde sülfat derişimi araştırma süresince istasyonlara göre $16,07 \pm 0,0 \mathrm{~g} / 1$ ile $58,22 \pm 0,0$ g/l arasında değişmiştir. Tuz Gölü’nün genel sülfat derişimi ortalaması ise $20,65 \pm 0,0 \mathrm{~g} / 1$ ile $39,55 \pm 0,0 \mathrm{~g} / 1$ arasında olmuştur. Uyanık ve Şen (1978) gölde sülfat derişiminin 4,7-44,5 g/l arasında değiştiğini bildirmişlerdir. Mayıs ve Haziran ayları gölün derin bölgesinde sırasıyla 7,6 g/l ve $6,4 \mathrm{~g} / 1$ ölçülmüştür bu değerler sı̆̆ bölgede 3,5 g/l ve 5,6 g/l olmuştur. Çamur ve Mutlu (1995), Nisan-Temmuz ayları arasinda sı ̆̆ bölgede sülfat derişiminin 6,6 g/1 -19,09 g/l, derin bölgede ise Mayıs-Temmuz ayları arasında 2,6 g/l-6,10 g/l arasında değiştiğini ve aylara bağlı artış eğilimi gösterdiğini bildirmişlerdir. Eskandari (2014), sülfat derişimlerini en düşük Mayıs ayında 3,125 g/l, en yüksek Ekim ayında 8,872 g/1 ölçmüştür. $\mathrm{Bu}$ çalışmada saptanan sülfat değerleri, araştırmacıların bildirdikleri değer aralıklarının üzerinde olup, genel olarak araştırma süresince her iki bölgede saptanan sülfat değerleri birbirine yakın olmuştur. Buna göre sülfat değerleri son yıllarda artmış olup, Akın (2019)'ın bildirdiği gibi bunun iklimsel ve çevresel faktörlerden kaynaklanmış olabileceği düşünülmektedir. Suyun doğal anyonlarından olan sülfatın, doğal sularda biyolojik verimin artması için bulunması gerekir. Sülfatın ortamda yeterince bulunmaması fitoplankton gelişimini engeller ve bitkilerin büyümesini yavaşlatır. Doğal göllerin sülfat değerleri 3-30 mg/L arasındadır (Atıcı ve Obalı, 1999). Bununla birlikte, Vanchaecke et al. (1984), Artemia bolluğunun sülfat içeren sularda, klorür içeren sulara göre daha düşük olduğunu bildirmişlerdir.

Tuz Gölü'nde bikarbonat ortalama değerleri araştırma süresince istasyonlarda $0,118 \pm 0,0 \mathrm{~g} / 1$ ile $0,680 \pm 0,0 \mathrm{~g} / 1$ arasında değişmiştir. Gölde araştırma süresince bikarbonat değerlerinin genel ortalamas $10,157 \mathrm{~g} / 1$ ile 0,280 g/1 arasında olmuştur. Değerler Mayıs ayına kadar yükselme, sonrasında azalma eğilimi göstermiştir. Uyanık ve Şen (1978) gölde bikarbonat derişiminin 0,090,360 g/l arasında değiştiğini bildirmişlerdir. Mayıs ve Haziran aylarında sirasıyla derin bölgede $0,128 \mathrm{~g} / 1$ ve $0,09 \mathrm{~g} / 1, \quad$ sığ bölgede ise $0,123 \mathrm{~g} / 1$ ve $0,134 \mathrm{~g} / 1$ olarak ölçülmüştür. $\mathrm{Bu}$ araştırmada ise derin bölgede mayıs ve haziran ayılarında bikarbonat ortalaması sırasıyla 0,192 $\mathrm{g} / 1$ ve $0,22 \mathrm{~g} / 1$, siğ bölgede ise sirasiyla $0,22 \mathrm{~g} / 1$ ve 0,38 g/1 olmuştur. Eskandari (2014), bikarbonat derişimlerini en düşük kasım ayında 0,095 $\mathrm{g} / \mathrm{l}$, en yüksek ağustos ayında 0,226 g/l olarak bildirmişlerdir. Bikarbonat değerlerine ilişkin sonuçlar diğer çalışmalarla benzer bulunmuştur. 
Bikarbonat değerleri, ilkbahardan yaz aylarına geçişte artış göstermiş olup, ilkbaharda karbonat çökelmesinden kaynaklı bikarbonatın geçici olarak azalma gösterdiği bildirilmektedir (Uygun ve Şen 1978). Bununla birlikte, Artemia bikarbonat içeren sularda bulunup, karbonatl sularda rastlanmamaktadir (Cole and Brown, 1965).

Tuz Gölü’nde dominant katyon olarak kalsiyum derişimleri istasyonlarda $0,85 \pm 0,0$ ile $1,48 \pm 0,0$ g/l arasında değişmiştir. Tuz Gölü'nün ortalama kalsiyum derişimi ise 1,02 g/l ile 1,21 g/l arasında olmuştur. Uygun ve Şen (1978) gölde kalsiyum değerlerini 0,140-1,130 g/l, Eskandari (2014) 0,99-3,25 g/1 olarak bildirmişlerdir. Bu çalışmada elde edilen ortalama kalsiyum değerleri Uygun ve Şen (1978) ile benzer olmuştur. Uygun ve Şen (1978) ve Çamur ve Mutlu (1995), derin bölgede kalsiyum değerlerinin ana bölgeye göre düşük $(0,30-0,40 \mathrm{~g} / \mathrm{l})$ olduğunu, bildirmişlerdir. $\mathrm{Bu}$ çalışmada da derin bölgenin kalsiyum değerleri nispeten düşük bulunmuş, ancak belirgin bir farklılık gözlenmemiştir.

Tuz Gölü'nde sodyum derişimleri $82,2 \pm 0,0$ $\mathrm{g} / 1$ ile $119,4 \pm 0,0 \mathrm{~g} / 1$ arasında değişmiştir. Tuz Gölü'nün ortalama sodyum derişimi ise 90,06 $\mathrm{g} / 1$ ile 118,29 g/l arasında olmuştur. Uygun ve Şen (1978), gölde sodyum değerlerini 73,3 g/1 ile 115,0 g/1 arasında olduğunu bildirmişlerdir. Mayıs ve Haziran aylarında derin bölgede sirasiyla $28 \mathrm{~g} / 1$ ve 56,5 g/1, sı ̆ bölgede ise 101,25 g/l ve 111,2 g/l olduğu kaydedilmiştir. Çamur ve Mutlu (1995), aynı şekilde Nisan Temmuz aylarında sı̆̆ bölgede ortalama $\mathrm{Na}$ değerini $106,7 \mathrm{~g} / 1$, derin bölgede ise $40 \mathrm{~g} / 1$ civarında bildirmişlerdir. Eskandari (2014), sodyumun Tuz Gölü'nde 70 g/l-110 g/l arasında değiştiğini kaydetmişlerdir. $\mathrm{Bu}$ çalışmada elde edilen veriler diğer çalışmalarla karşılaştırıldığında, değer aralıklarının benzer olduğu, gölde bahar aylarında nisbeten düşük olan sodyum derişiminin yaz aylarında daha yüksek olduğu görülmektedir. Bununla birlikte, bu çalışmada sı ̆ ve derin bölgeler arasında belirgin bir farklılık kaydedilmemiştir.

Tuz Gölü'nde potasyum derişimleri $0,50 \pm 0,0$ $\mathrm{g} / 1$ ile 5,01 $\pm 0,0 \mathrm{~g} / 1$ arasında değişmiştir. Tuz Gölü'nün ortalama potasyum derişimi $0,52 \pm 0,0$ ile 2,22 $\pm 0,0$ arasında olmuştur. Uygun ve Şen (1978), gölde potasyumun 0,8 g/1 ile $3,3 \mathrm{~g} / 1$ arasında değiştiğini bildirmişlerdir. Mayıs ve Haziran aylarında derin bölgede sirasıyla 0,3 $\mathrm{g} / 1$ ve $0,85 \mathrm{~g} / 1$, sı ̆ bölgede ise $1,2 \mathrm{~g} / 1$ ve 0,65 g/l olduğu kaydedilmiştir. Çamur ve Mutlu (1995), aynı şekilde Nisan -Temmuz aylarında sığ bölgede ortalama $\mathrm{K}^{+}$değerini 1,64 g/l, derin bölgede ise $0,48 \mathrm{~g} / 1$ civarında bildirmişlerdir. Eskandari (2014), potasyumun Tuz Gölü'nde 0,75-3,73 g/l arasında değiştiğini kaydetmiştir. $\mathrm{Bu}$ araştırmanın sonuçlarına göre mart ayı dışında sı̆̆ bölgede potasyum değerleri derin bölgeye göre daha yüksek olmuştur.

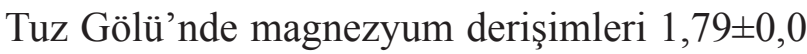
$\mathrm{g} / 1$ ile $15,08 \pm 0,0 \mathrm{~g} / 1$ arasında değişmiştir. Tuz Gölü'nün ortalama magnezyum derişimi

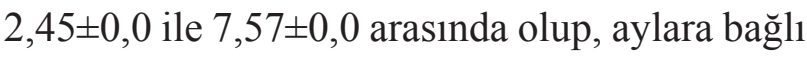
artış göstermiştir. Eskandari (2014), magnezyum değerlerinin gölde 2,202-6,136 g/1 arasında bildirmiştir. Uygun ve Şen (1978), göldeki iki yıllık çalışmalarında magnezyumun 1,6 g/l ile 
25,3 g/l arasında değiştiğini bildirmişlerdir. Mayıs ve Haziran aylarında derin bölgede sirasiyla 3,3 g/1 ve 2,4 g/l, siğ bölgede ise 2,1 $\mathrm{g} / 1$ ve $1,9 \mathrm{~g} / 1$ olduğu kaydedilmiştir. Çamur ve Mutlu (1995), aynı şekilde Nisan -Temmuz aylarında sığ bölgede ortalama Mg değerini 4,90 $\mathrm{g} / \mathrm{l}$, derin bölgede ise 1,56 g/l civarında olduğunu bildirmişlerdir. Bu çalışmada, elde edilen veriler Eskandari (2014) ile benzerlik göstermiş ancak derin ve sı̆g bölgelerdeki ortalama magnezyum değerleri Uygun ve Şen'e göre farklılık göstermektedir. Derin bölgedeki magnezyum derişimi düşüktür.

Tuz göllerinde, iyon kompozisyonu biyota kompozisyonunu etkilemektedir (Williams, 1998). Artemia habitat1, sodyum klorür baskınlığ1 olan sularla karakterizedir (Cole and Brown, 1965). Ayrıca Artemia habitatlarının iyon kompozisyonu değişkenlik göstermekle birlikte, Artemia'da morfolojik farklılıklara da neden olduğu bildirilmektedir (Hontoria and Amad, 1992). İyon konsantrasyonunun yüksek olduğu sularda, bitkiye rastlanmaz ve tür çeşitliliği düşüktür (Arora and Mehda, 2009).

Tuz Gölü’nde, 1994 yılından günümüze kadar, Artemia populasyonunun durumuna ilişkin çeşitli araştırıcılar tarafindan çalışmalar yapılmıştır. Başbuğ (1994), Artemia populasyonunun sadece gölün doğu yakasında, yer alan Devekonağ1 ve Çalören arasındaki 10 km'lik kıyı şeridinde yayılım gösterdiğini, araştırmanın yapıldığ yıl (birey sayısının ise 6-468 birey $/ \mathrm{m}^{3}$ ) üreme dönemlerinin Nisan-Temmuz ayları arasında olduğunu ve populasyonun iki kuşak ile temsil edildiğini bildirmiştir.
Tuz Gölü'nün bazı anyon ve katyonlarının araştırıldığ 1 bu çalışma ile eş zamanlı olarak Kırkağaç et al. (2017) tarafindan, Artemia sp.populasyon yapısı araştırılmış, gölün diğer bazı fiziksel ve kimyasal özellikleri de ortaya konulmuştur. Söz konusu araştırma kapsamında örneklerde kiste rastlanmazken, Artemia sp. sadece bir kez Mart ayındaki ikinci örneklemede gölün derin bölgesinde bulunan 5. istasyonda metanauplius formunda $\left(3,67 \times 10^{3}\right.$ birey $\left./ \mathrm{m}^{3}\right)$ bulunmuştur. Araştırma süresince, özellikle su sıcaklığı, çözünmüş oksijen ve tuzluluk değerleri son 20 yıla ilişkin verilerle karşılaştırıldığında artış göstermiş, su derinliği ise gölün tamamında azalmıștır.

\section{Sonuç}

Bu çalışma, Tuz Gölü'nde Artemia sp.'nın doğal alanından kaybolma tehlikesi gösterdiği 2014 yılında yapılmış olup, gölün sığ ve derin bölgelerinde belirlenen bazı anyon ve katyonların Artemia populasyonlarının varlığını etkileyici bir unsur olup olmadığını ortaya koyacak bir ön çalışma niteliğindedir. Bu çalışmada, göldeki bazı anyon ve katyon değerlerine ilişkin bulgular, Uygun ve Şen (1978)'in bulguları ile karşılaştırıldığında, yaklaşık son 40 yılda sözü edilen iyon değerlerinde belirgin bir değişim olmadığını göstermektedir. Göllerde, iyon kompozisyonu, pH, hidrolojik koşullar, coğrafi konum, biyolojik etkileşim ve özellikle insan etkileri göllerde canlı topluluklarının belirleyicileridir. $\mathrm{Bu}$ bağlamda, gölde bu süreçte Artemia populasyonuna rastlanmaması konusunda anyon ve katyon düzeylerinin önemli 
bir payı olmadığı, ancak Tuz Gölü'nün fiziksel, kimyasal ve biyolojik açıdan uzun dönemli izlenmesi gerektiği düşünülmektedir.

\section{Kaynaklar}

Akın, B. (2019). Tuz Gölü Havzası'nın Kuraklık Analizi. Ulusal Çevre Bilimleri Araştırma Dergisi, 2(1):44-56.

Anonim (2004). Tuz gölü Özel Çevre Koruma Bölgesinin Toprak ve Arazi kalite Sınıflaması ile Alternatif Tarımsal uygulamalarının belirlenmesi Projesi Sonuç raporu. Özel Çevre Koruma Kurumu Başkanlığı, 391 s.

Anonim (2007). Tuz Gölü Biyolojik Çeşitliliği Tespiti Projesi Final Raporu, Biyolojik Çeşitliliğin Tespiti: Tuz Gölü Projesi. Özel Çevre Koruma Kurumu Başkanlığı, AKS Planlama Mühendislik, 27 s.

APHA (1980). Standard Methods for the Examination of Water and Wastewater, 15th Edition, American Public Health Association publication. Washington DC.

Arora, M. and Mehra, N.K. (2009). Seasonal Dynamics of Zooplankton in a Shallow Eutrophic, Man-Made Hyposaline Lake Delhi (India): Role of Environmental Factors. Salt Lake Research, 626:27-40.

Atıcı,T.ve Obal,O.(1999). SusuzGöleti(Ankara) Algleri ve Su Kalite Değerlendirmesi. G.Ü. Gazi Eğitim Fakültesi Dergisi, 19(3): 99104.

Başbuğ, Y. (1994). Tuz Gölü'nde Yaşayan Artemia salina (L., 1758)'nın Biyolojik
Özellikleri ve Sistlerinden Laboratuar Koşullarında Larva Üretilmesi. Yüksek Lisans Tezi. Hacettepe Üniversitesi Fen Bilimleri Enstitüsü.81 s.

Başbuğ, Y. and Demirkalp, F.Y. (1997). A Note on the Brine Shrimp Artemia in Tuz Lake. Hydrobiologia, 263:45-51.

Başbuğ, Y. (1999a). Tuz Gölü'nde Yaşayan Artemia salina'nın (L., 1758) Bazı Biyolojik Özellikleri. Turkish Journal of Zoology, 23(2): 617-624.

Başbuğ, Y. (1999b). Tuz Gölü'nde Yaşayan Artemia salina (L.. 1758)'nın Üreme Özellikleri. Turkish Journal of Zoology, 23(2): 635-640.

Cole, G.A. and Brown, R.I. (1967). Chemistry of Artemia habitats. Ecology, 48: 858-86.

Çamur, M.Z.ve Mutlu,H.(1995). Tuz Gölü'ndeki mineral çökeliminin termodinamik değerlendirilmesi. Türkiye Jeoloji Bülteni, 38(2): 67-73.

Eskandari, A. (2014). Türkiye'de Kiyısal ve Karasal Tuzlu Göllerde Yayılım Gösteren Artemiapopulasyonlarının Ekolojik, Sitogenetik, Moleküler, Morfometrik Yöntemler Kullanılarak Araştırılması ve Biyotopların Hidrobiyolojik Yönden Incelenmesi. Doktora Tezi. Hacettepe Üniversitesi, Fen Bilimleri Enstitüsü, Ankara. 172 s.

Eskandari, A. and Saygi, Y. (2019). Ecological Surveys on the Parthenogenetic Artemia Populations in the Hypersaline Lakes of Anatolia, Turkey. Turkish Journal of 
Zoology, 43(4): 367-378.

Hontaria, A. and Amad, F. (1992). Morphological Characterization of Adult Artemia (Crustacea, Branchiopoda) from Different Geographical Origin: Mediterranean populations. Journal of Plankton Research, 14:1461-1471.

Kesici, T. ve Kocabaş, Z. (2007). Biyoistatistik. Ankara Üniversitesi Eczacilık Fak. Biyoistatistik Yayın No:94, Ankara, 369 s.

Kılıç, A.M. ve Uyanık, E. (2001). Tuz Gölü’nde Oluşan Kirlenmenin Göl Üzerindeki Etkilerinin Araştırılması. 4. Endüstriyel Hammaddeler Sempozyumu,18-19 Ekim, İzmir, 135-145.

Kırkağaç, M.U., Gümüş, E. ve Yokuş, G. (2017). The Effects of Environmental Factors on Artemia Population in Tuz Lake (Central Anatolia, Turkey). Iğdır Üniversitesi Fen Bilimleri Enstitüsü Dergisi, 7(2): 303-312.

Köylü, M.K. (2017). Tuz Gölü’nün Finansal Yatırım Değeri ve Ekonomik Büyümeye Katk1s1. International Journal of Academic Value Studies, 3(15):127-137.

Litvinenko, L., Kozlov, A.V., Kovalenko, A.I. and Bauer, D.S. (2007). Salinity of Water as a Factor to Determine the Development of the Brine Shrimp Artemia Populations in Siberian Lakes. Hydrobiologia, 576(1): 95101.

Örmeci, C. ve Ekercin, S. (2005). Uzaktan Algılama Tekniği ile Tuz Gölü'nde Su Kalitesi Değişim Analizi. TMMOB Harita ve Kadastro Mühendisleri Odası 10. Türkiye
Harita Bilimsel ve Teknik Kurultayı Mart 2005, Ankara.

Uygun, A. ve Şen, E. (1978). Tuz Gölü Havzası ve Doğal Kaynakları I: Tuz Gölü Suyunun Jeokimyas1. Türkiye Jeoloji Kurumu Bülteni,21: 113-120.

Vanhaecke, P., Tackaert, W. and Sorgeloos, P. (1984). International Study on Artemia XLVII. Combined Effects of Temperature and Salinity on the Survival of Artemia of Various Geographical origin. J.Exp. Mar. Biol. Ecol., 80:259-275.

Williams, W.D. (1998). Salinity as a Determinant of the Structure of Biological Communities in salt lakes. Hydrobiologia, 381:191-201.

Yokuş, G. and Kırkağaç, M. (2019). The Status of Artemia Population in Tuz Lake (Central Anatolia, Turkey). Biological Diversity and Conservation, 4(5): 7-12. 